\title{
LIBERDADES BÁSICAS, JUSTIFICAÇÃO PÚBLICA E PODER POLÍTICO EM JOHN RAWLS
}

\author{
Denilson Luis Werle \\ Universidade Federal de Santa Catarina
}

\begin{abstract}
A common objection to Rawls' political liberalism is to say that in the conception of justice as fairness a set of fundamental individual rights have an a priori primacy on the rights of communication and participation expressed in the democratic process of political legitimation. Consequently, there would be an priority of private autonomy over public autonomy, so that the basic liberal rights would limit ex ante the democratic self-legislation expressed in the ideal of popular sovereignty, so that the political liberties would play a merely instrumental role in the preservation of others liberties, as if there were a sphere of a pre-political liberty inaccessible to democratic self-legislation. The aim of this paper is to show that this objection is not valid if we consider the complex conception of liberty and autonomy developed by Rawls in his discussion of the notion of basic liberties, their priority and their incorporation into the basic structure of society. It shows the intertwining of public justification of the principles of justice and the democratic process of political legitimation.
\end{abstract}

KEYWORDS: Rawls, basic liberties, democracy, public justification, political legitimation.

RESUMO: Uma objeção comum ao liberalismo político de John Rawls consiste em afirmar que na concepção de justiça como equidade um conjunto os direitos individuais fundamentais teria uma primazia apriori sobre os direitos de comunicação e participação expressos no procedimento democrático de legitimação política. Consequentemente, haveria uma prioridade da autonomia privada sobre a autonomia pública, de modo que os direitos liberais básicos limitariam ex ante a autolegislação democrática expressa no ideal da soberania popular, e as liberdades políticas, por sua vez, desempenhariam um papel meramente instrumental na preservação das demais liberdades, como se existisse uma esfera de liberdade prepolítica inacessível à autolegislação democrática. 0 objetivo do artigo é mostrar que essa objeção não é válida se considerarmos a concepção complexa de liberdade e de autonomia desenvolvida por Rawls em sua argumentação sobre a noção de liberdades básicas, sua prioridade e sua incorporação na estrutura básica da sociedade. 
Mostra-se o entrelaçamento da justificação pública dos princípios de justiça e o procedimento democrático de legitimação política.

PALAVRAS-CHAVE: Rawls, liberdades básicas, democracia, justificação pública, legitimação política.

No prefácio a edição revista de Uma teoria da justiça, Rawls esclarece alguns pontos importantes sobre o objeto e finalidade de sua teoria da justiça como equidade. Antes de mais nada é importante ter em mente que considera as ideias e objetivos centrais da sua teoria da justiça como equidade como aqueles apropriados para "uma concepção filosófica da justiça para uma democracia constitucional”. A esperança de Rawls "é a de que a justiça como equidade pareça razoável e útil, ainda que não totalmente convincente, para uma grande gama de orientações política ponderadas e, portanto, expresse o núcleo comum da tradição democrática" ${ }^{1}$. Um dos pressupostos da teoria de Rawls é o de que tem de haver um vínculo necessário entre justiça e a estrutura básica de uma sociedade democrática. Nesse sentido, uma das tarefas fundamentais da filosofia política é fornecer uma base pública de justificação para os próprios cidadãos chegarem a acordos políticos sobre as questões políticas fundamentais que dizem respeito aos seus direitos e deveres recíprocos como pessoas livres e iguais membros plenos de uma comunidade política e à distribuição dos benefícios e encargos resultantes da cooperação social voltada para vantagens mútuas de todos.

É importante considerar que Rawls não pretende elaborar uma concepção moral abrangente da justiça que seja aplicável a um amplo leque de questões práticas, desde juízos morais sobre a vida boa até problemas mais amplos da relação moral, política e direito. Seu objeto é mais específico: "o objeto primário da justiça é a estrutura básica da sociedade, ou mais exatamente, a maneira pela qual as instituições sociais mais importantes distribuem direitos e deveres fundamentais e determinam a divisão de vantagens decorrentes da cooperação social” ${ }^{2}$. Assim, o que a teoria da justiça

\footnotetext{
1 RAWLS, J. "Prefácio à edição brasileira". In: RAWLS, J. . Uma teoria da justiça. Trad. de Almiro Pisetta e Lenita M. R .Esteves. São Paulo: Martins Fontes, 2002. p.xiii-xiv.

2 Idem, p.8. O conceito de estrutura básica é, como reconhece o próprio Rawls, um tanto vago. Nem sempre fica claro quais instituições ou quais de suas características deveriam ser incluídas. Numa definição aproximada, Rawls entende por instituições mais importantes "a constituição política e os principais arranjos econômicos e sociais, a proteção legal da liberdade de pensamento e de consciência,
} 
de Rawls pretende é justificar um conjunto de princípios capaz de fornecer um ponto de vista comum a partir do qual reivindicações conflitantes dos cidadãos possam ser julgadas. Além de um procedimento de justificação, a concepção da justiça como equidade oferece também um padrão pelo qual se devem avaliar os aspectos da estrutura básica quando questões políticas fundamentais estiverem em jogo ${ }^{3}$. Este padrão não deve ser estendido para os princípios que definem outras virtudes morais das pessoas, nem ser usado para resolver todos os dilemas morais na vida cotidiana. Trata-se, portanto, de um padrão voltado paras as principais instituições da sociedade, e apenas indiretamente para os indivíduos, à medida que estes vivem e levam adiante seus planos de vida sob as regras públicas estabelecidas por aquelas instituições.

Esse modo de delimitar o escopo e finalidade da teoria da justiça deriva do próprio modo de Rawls entender as tarefas da filosofia política numa democracia constitucional. Uma das tarefas primordiais da filosofia política consiste em formular uma espécie de diagnóstico de seu tempo, isto é, "debruçar-se sobre certas questões que suscitam controvérsias políticas agudas polarizadas e examinar se alguma base subjacente de acordo pode ser descoberta e se um modo mutuamente aceitável de resolvê-las pode ser publicamente estabelecido. Alternativamente, se essas questões não podem ser resolvidas, como pode ocorrer, talvez se possa diminuir suficientemente a divergência de opinião de modo a que a cooperação política com base no respeito mútuo possa ser mantida". 4 Trata-se de sua "função prática resultante dos conflitos políticos irreconciliáveis e da necessidade de resolver o problema da ordem". ${ }^{5}$

Dentre as controvérsias políticas mais profundas latentes na cultura política moderna, Rawls destaca como uma das mais importantes o

os mercados competitivos, a propriedade particular no âmbito dos meios de produção e a família monogâmica" (idem, p.8).

${ }^{3}$ Essas questões referem-se aos "elementos constitucionais essenciais" (os princípios fundamentais que especificam a estrutura geral do Estado e do processo político; as prerrogativas do legislativo, do executivo e do judiciário; 0 alcance da regra da maioria; os direitos e liberdades fundamentais e iguais de cidadania que as maiorias legislativas devem respeitar, tais como o direito ao voto e á participação política, a liberdade de consciência, a liberdade de pensamento e de associação, assim como as garantias do rule of law.) e "às questões de justiça básica" (a distribuição dos bens sociais básicos).

${ }^{4}$ RAWLS, J. "Justiça como equidade: uma concepção política, não metafísica". Lua Nova, n. 25, 1992, p.29.

${ }^{5}$ RAWLS, J. Justiça como equidade: uma reformulação. Tradução de Cláudia Berliner. Revisão técnica e da trad. Álvaro de Vita. São Paulo: Martins Fontes, 2003, p.1. 
desacordo sobre "como os valores da liberdade e da igualdade são realizados, da melhor forma possível, na estrutura básica da sociedade". ${ }^{6}$ As discussões na filosofia política moderna têm demonstrado que não há nenhum "acordo público sobre como as instituições básicas devem ser organizadas para melhor se adequarem à liberdade e à igualdade da cidadania democrática". ${ }^{7}$ Rawls refere-se aqui ao conflito clássico entre a tradição liberal, derivada de Locke, que acentua a "liberdade dos modernos" - liberdade de pensamento e liberdade de consciência, certos direitos básicos da pessoa e de propriedade, o primado da lei - e a tradição republicana, vinculada a Rousseau, que acentua a "liberdade dos antigos" - as liberdades políticas iguais e os valores da vida pública. A tarefa da filosofia política é, portanto, reconciliar essas duas tradições, combinando-as num procedimento comum de fundamentação de princípios de justiça.

Os princípios de justiça e o procedimento de sua justificação apresentados por Rawls na sua concepção de justiça, fundamentada segundo os ideais morais presentes na tradição do liberalismo político, pretendem ser uma solução para essa controvérsia. Porém, tanto para liberais quanto para não-liberais, Rawls não conseguiu uma reconciliação satisfatória dessas duas tradições. Uma objeção comum ao liberalismo político de John Rawls afirma que, em sua concepção política da justiça, um conjunto os direitos individuais fundamentais tem a prori uma primazia sobre os direitos de comunicação e participação expressos no procedimento democrático de legitimação. Conseqüentemente, a teoria de Rawls daria prioridade a autonomia privada sobre a autonomia pública, de modo que os direitos liberais básicos limitariam autolegislação democrática expressa no ideal da soberania popular, e as liberdades políticas, por sua vez, desempenhariam um papel meramente instrumental na preservação das demais liberdades, como se existisse uma esfera de liberdade prepolítica inacessível à autolegislação democrática. ${ }^{8} \mathrm{O}$ que se pretende mostrar aqui é que essa objeção não é válida

\footnotetext{
6 "Justiça como equidade...",op. cit., p. 29.

7 Justiça como equidade..., op. cit., p.2.

${ }^{8}$ Como exemplo, essa é uma das críticas feitas por Habermas, para quem Rawls segue a intuição correta de Rousseau e Kant em deduzir a liberdade dos modernos e dos antigos a partir de uma mesma raiz: o conceito de autonomia. Porém, a teoria de Rawls acabaria dando "uma prioridade aos direitos básicos liberais que deixa, em certa medida, o processo democrático na sombra [...] : "pois quanto mais erguem o véu de ignorância e quanto mais assumem um forma de carne e osso, os cidadãos de Rawls se encontram mais profundamente imersos na hierarquia de uma ordem progressivamente institucionalizada por sobre suas cabeças. Assim, a teoria priva os cidadãos de uma boa parte daquelas
} 
se considerarmos a concepção complexa de liberdade e de autonomia desenvolvida por Rawls em sua argumentação sobre a noção de liberdades básicas, sua prioridade e sua incorporação na estrutura básica da sociedade. A partir da reconstrução dos propósitos básicos do liberalismo político de Rawls e de alguns de seus conceitos fundamentais (o de estrutura básica da sociedade, pessoa moral e razão pública) é possível mostrar que (a) a liberdade é um padrão de convivência determinado por diversas formas sociais, que se realiza em várias instituições e práticas políticas, o que permite pensar a liberdade em toda sua extensão: como liberdade moral do indivíduo autônomo, liberdade ética de auto-realização, liberdade jurídica da pessoa de direito e a liberdade política presente na soberania popular; e (b) existe um entrelaçamento entre autonomia privada e autonomia pública no liberalismo político, uma vez que as liberdades básicas se encontram incorporadas na constituição e são protegidas por direitos constitucionais com base nas deliberações e juízos dos cidadãos ao longo do tempo; estão sujeitas ao poder constituinte do povo para formar, ratificar e emendar uma constituição. Desenvolver essa interpretação do liberalismo político de Rawls pode lançar novas luzes na compreensão da ideia de consenso sobreposto, de razão pública e do princípio liberal de legitimidade diante da crítica comum de que tais ideias seriam demasiado restritivas, estáticas e discriminatórias em relação às diferentes doutrinas religiosas, filosóficas e morais abrangentes.

Considerando principalmente o texto "As liberdades fundamentais e sua prioridade”, conferência VIII do Liberalismo Político, e a réplica de Rawsl a Habermas, é possível encontrar uma concepção mais complexa de liberdade no liberalismo político de Rawls, cuja concepção de justiça procura sistematizar as diferentes dimensões de liberdade, sem que uma seja

intuições que cada geração teria de assumir como suas. Da perspectiva da teoria da justiça, o ato de fundar um Estado de direito democrático não pode nem precisa repetir-se sob as condições de uma sociedade já ordenada de modo justo, o processo de realização dos direitos não pode nem precisa ser questionado em longo prazo. Os cidadãos não podem experimentar este processo, tal como exigiriam as circunstâncias históricas cambiantes, como um processo aberto e incompleto. Eles não podem reavivar as brasas do núcleo radical democrático da posição original na vida real de sua sociedade, pois de sua perspectiva todos os discursos de legitimação essenciais já ocorreram no seio da teoria; e os resultados dos debates teóricos se encontram já sedimentados na constituição. Uma vez que os cidadãos não podem conceber a constituição como um projeto, o uso público da razão não tem realmente o sentido de uma realização da autonomia política, mas meramente para manutenção pacífica da estabilidade política." Habermas, Jürgen. "Reconciliación mediante el uso público de la razón" In: HABERMAS, J.; RAWLS, J. (1998). Debate sobre el liberalismo político. Tradução de Gerard Vilar Roca. Barcelona: Paidós, 1998, p.66-67. 
subordinada a outra. Ao contrário de um liberalismo mais tradicional, baseado num conjunto de direitos individuais fundamentais, na formulação de Rawls a determinação do sistema adequado de liberdades fundamentais não pode ser pensado como tendo a função de maximizar um valor absoluto (a liberdade como tal); antes, trata-se de justificar um conjunto de liberdades fundamentais necessárias para o desenvolvimento adequado das capacidades razoáveis e racionais da pessoa autônoma, como membro pleno de uma sociedade democrática. O que se pode mostrar, então, é que não é justa a crítica feita a Rawls de que em sua teoria da justiça os direitos liberais modernos (autonomia privada) têm a prori uma primazia sobre o os direitos de comunicação e participação expressos no procedimento democrático de legitimação (autonomia pública, soberania popular), isto é, que os direitos liberais básicos limitam a partir de fora a autolegislação democrática, como se existisse uma esfera de liberdade pré-política que não estaria acessível à

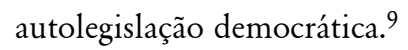

$\mathrm{Na}$ conferência VIII do Liberalismo Político Rawls afirma que foi levado a modificar sua explicação da liberdade a partir da crítica que lhe foi feita por Hart no artigo Rawls on Liberty and its priority. ${ }^{10}$ Hart apontou duas falhas graves no argumento de Rawls: 1) que as razões pelas quais as partes na posição original adotariam as liberdades básicas e concordariam com sua prioridade não estavam suficientemente explicitadas em Uma Teoria da Justiça; 2) que quando os princípios de justiça são aplicados nos estágios constitucional, legislativo e judicial não é fornecido um critério suficiente para saber como as liberdades básicas devem ser especificadas e ajustadas umas às outras quando são conhecidas as circunstâncias sociais da sociedade. Rawls pretende corrigir essas duas falhas tornando mais preciso o argumento a favor dos dois princípios de justiça, mostrando como as liberdades básicas e os fundamentos para sua prioridade podem ser justificados a partir da concepção de cidadãos como pessoas livres e iguais em conjunto com uma explicação dos bens básicos e uma certa concepção de cooperação social.

Para dar uma resposta consistente a Hart, Rawls começa reformulando os princípios de justiça e esclarecendo qual o conceito de

\footnotetext{
${ }^{9}$ Claro, isso não significa dizer que Habermas não tenha razão nas demais críticas feitas a Rawls.

10 HART, H. L. A. "Rawls on liberty and its priority" in: DANIELS, N. (ed.) Reading Rawls. Oxford: Basil Blackwell, 1975.
} 
pessoa que está na base da sua concepção de justiça. Os dois princípios passam a ter a seguinte formulação:

a. Toda pessoa tem um direito igual a um sistema plenamente adequado de liberdades fundamentais iguais que seja compatível com um sistema similar de liberdades para todos.

b. As desigualdades sociais e econômicas devem satisfazer duas condições. A primeira é que devem estar vinculadas a cargos e posições abertos a todos em condições de igualdade equitativa de oportunidades; e a segunda é que devem redundar no maior benefício possível para os membros menos privilegiados da sociedade. ${ }^{11}$

A alteração ocorre principalmente no primeiro princípio, onde a expressão "mais abrangente sistema total", presente na primeira formulação do princípio em Uma teoria da justiça, é substituída por "sistema plenamente adequado", e também é inserida "que seja" antes da palavra "compatível". O propósito dessa reformulação é mostrar justamente que Rawls não quer atribuir "prioridade alguma à liberdade como tal; se assim fosse, o exercício de uma coisa chamada 'liberdade' teria um valor preeminente e seria a meta principal, se não a única, da justiça social e política". ${ }^{12}$ Se assim fosse, o liberalismo político de Rawls acabaria sendo igual aos demais liberalismos éticos-políticos abrangentes, que defendem algum tipo de ideal moral abrangente.

Rawls fornece uma lista das liberdades fundamentais iguais no primeiro princípio de justiça: a liberdade de pensamento e de consciência; as liberdades políticas e a liberdade de associação, assim como as liberdades especificadas pela liberdade e integridade da pessoa; e, finalmente, os direitos e liberdades abarcados pelo império da lei, ${ }^{13}$ não atribuindo ou justificando nenhuma forma de hierarquização entre elas. O que importa é a formação e institucionalização de um sistema das liberdades, que permanece em certa medida indeterminado quanto à combinação das várias liberdades conflitantes. Ao dizer que não atribui nenhuma prioridade à liberdade como tal Rawls argumenta que sua interpretação das liberdades fundamentais segue

\footnotetext{
${ }^{11}$ Rawls, John. O liberalismo político. Trad. Dinah de Abreu Azevedo. São Paulo: Ática, 2000, p.345.

12 idem, p. 345.

13 Idem, p. 345.
} 
a tradição do pensamento democrático, cujo foco sempre esteve voltado para "a aquisição de certas liberdades específicas e garantias constitucionais, como as encontradas, por exemplo, nas várias cartas de direitos e declarações de direitos do homem". ${ }^{14}$ Dado que as várias liberdades fundamentais estão fadas a conflitar umas com as outras, é necessário que as regras institucionais que definem essas liberdades devam ser ajustadas de modo que se encaixem num sistema coerente de liberdades garantido igualmente a todos os cidadãos, sistema que deve estar aberto a revisões e adaptações conforme mudem as condições sociais necessárias para seu exercício duradouro, respeitando a esfera de aplicação de cada liberdade. ${ }^{15}$

Rawls continuará a manter a tese da prioridade da liberdade no sentido de que uma liberdade só pode ser limitada ou negada em nome de uma outra ou de outras liberdade fundamentais, e nunca por considerações de bem estar geral ou por valores perfeccionistas. Sendo que as liberdades fundamentais podem ser limitadas quando entram em choque entre si, nenhuma delas pode ser considerada absoluta. Para justificar a prioridade das liberdades básicas Rawls esclarece qual o conceito de pessoa que está na base do liberalismo político. Além de serem vistas como cidadãos livres e iguais, as pessoas são tidas como cidadãos que possuem duas faculdades (ou capacidades) morais: a de terem um senso de justiça e a de formar, buscar e revisar uma concepção racional do bem. A lista de liberdades básicas sugerida por Rawls representa as condições sociais fundamentais para $\mathrm{O}$ desenvolvimento adequado e exercício pleno dessas duas capacidades da pessoa durante a vida inteira, fundamentais para o desenvolvimento de um senso de independência pessoal e de auto-respeito.

Mas, como justificar a própria ideia de pessoa? Certamente, afirma Rawls, existem muitos aspectos de nossa natureza que poderiam ser considerados como significativos para caracterizar a natureza humana: o homo politicus, o homo economicus, o homo faber. O que justifica o conceito de pessoa adotado por Rawls é o próprio propósito da justiça como equidade: "o objetivo é formular uma concepção de justiça política e social afim às convicções e tradições mais profundamente arraigadas de um Estado democrático moderno. O propósito de fazer isso é verificar se podemos

\footnotetext{
14 Idem, p. 346.

${ }^{15}$ Como veremos mais adiante, essa indeterminação e o conflito entre as liberdades são resolvidos não pela teoria, mas pelo poder político, exercido segundo um princípio liberal de legitimidade baseado na razão pública.
} 
resolver o impasse de nossa história política recente, qual seja, de que não há concordância sobre a forma pela qual as instituições básicas devem ser organizadas para se harmonizarem com a liberdade e igualdade dos cidadãos enquanto pessoas". ${ }^{16}$ Tendo esse propósito, o conceito de pessoa é justificado de duas formas: como uma ideia intuitiva presente na cultura política pública de uma democracia constitucional e como uma ideia da razão prática. ${ }^{17}$ Segundo Rawls, o conceito de pessoa é considerado como parte de uma concepção de justiça política e social, expressa a auto-compreensão prática implícita nas instituições, diz como os cidadãos devem ver a si mesmos e uns aos outros em suas relações políticas e sociais, da maneira especificada pela estrutura básica da sociedade. E esta é o objeto primeiro da justiça, e abrange, com vimos, as principais instituições sociais - a constituição, o regime econômico, a ordem legal, a especificação da propriedade e congêneres, e como essas instituições se combinam para formar um sistema. O que é próprio da estrutura básica é que ela oferece o

\footnotetext{
16 Idem, p. 354.

17 O construtivismo político afirma que "depois de obtido o equilíbrio reflexivo, se isso vier a acontecer, os princípios de justiça políica (o conteúdo) podem ser representados como o resultado de um certo procedimento de construção (a estrutura). Nesse procedimento, modelado de acordo com a posição original, os agentes racionais, enquanto representantes dos cidadãos e sujeitos a condições razoáveis, selecionam os princípios públicos de justiça que devem regular a estrutura básica da sociedade. Esse procedimento, assim conjecturamos, sintetiza todos os requisitos da razão prática e mostra como os princípios de justiça resultam dos princípios da razão prática conjugados às concepções de sociedade e pessoa, também elas ideias da razão prática". Idem, p. 134. Noutra passagem do mesmo livro, Rawls reforça essa ideia: "Podemos dizer, então, que as concepções de sociedade e pessoa, e o papel público dos princípios de justiça, são ideias da razão prática. Não só adotam uma forma que a razão prática requer para sua aplicação, como também proporcionam o contexto no qual as questões e problemas práticos surgem. [...] Sem as ideias de sociedade e pessoa, as concepções do justo e do bem não têm sentido. Essas ideias são tão básicas quanto aquelas de julgamento e inferência, e os princípios da razão prática". Idem, p. 156. Essas passagens indicam que a ancoragem histórica da dimensão kantiana não redunda numa concepção conservadora e contextualista da justiça, ou numa espécie de concepção realista da moral. Rawls se opõe expressamente ao realismo moral. O construtivismo kantiano sustenta que a objetividade moral deve ser compreendida segundo um ponto de vista social construído adequadamente, que todos poderiam aceitar. Fora do procedimento de construção dos princípios de justiça, não existem fatos morais. Como dito acima, esse procedimento é construído segundo ideias de sociedade e de pessoa que são simultaneamente ideias da razão prática - e, como tais, pressupostos indispensáveis na formação do juízo moral imparcial - e ideias intuitivas implícitas na cultura política das sociedades democráticas modernas. Portanto, Rawls parece ter em mente um procedimento complexo de justificação que procurar reunir, na base comum da ideia fundamental de sociedade como sistema de cooperação social equitativo e de pessoa moral livre e igual, uma interdependência "dialética" entre 0 ponto de vista moral do que é bom para todos e o ponto de vista do que é bom para nós. Trata-se de uma tentativa de mostrar que os princípios de justiça podem ser justificados "em todos os níveis de generalidade". Cf. WERLE, D. L.. Justiça e democracia. Ensaios sobre John Rawls e Jürgen Habermas. São Paulo: Esfera Pública, 2008.
} 
quadro para um sistema auto-suficiente de cooperação para todos os objetivos essenciais da vida humana, objetivos esses realizados pelo grande número de associações e grupos no interior desse quadro.

Portanto, o foco da justiça como equidade recai nas pessoas não apenas enquanto indivíduos racionais abstratos orientados apenas pelas suas preferências privadas (autonomia privada), mas enquanto pessoas capazes de serem membros normais e plenamente cooperativos da sociedade (na sua autonomia social e pública). A capacidade para a cooperação social é vista como fundamental, uma vez que se adote a estrutura básica como objeto primeiro da justiça. Para as pessoas serem vistas dessa maneira, Rawls atribui a elas duas capacidades morais - o senso de justiça (a disposição para seguir os princípios de justiça e de receber e oferecer razões para justificá-los) e a concepção do bem (formar, rever e perseguir um determinado plano racional de vida). O desenvolvimento dessas duas capacidades morais é uma condição necessária e suficiente para alguém ser considerado um membro pleno e igual na sociedade democrática: Para Rawls essas duas capacidades morais constituem a base da cidadania igual, que implica poderem participar efetivamente da cooperação social voltada para a vantagem mútua, mas com base no respeito mútuo, com a disposição de respeitar os termos equitativos e apropriados de cooperação. Já nessa concepção de pessoa moral, vê-se a pretensão de Rawls em harmonizar autonomia pública e autonomia privada, o razoável e o racional na especificação das liberdades básicas apropriadas a essa concepção de pessoa moral.

Diante disso, o "problema de especificar as liberdades fundamentais e de justificar sua prioridade pode ser visto como o de determinar os termos equitativos e apropriados de cooperação social com base no respeito mútuo". ${ }^{18}$ Até as guerras religiosas dos séculos XVI e XVII, esses termos equitativos eram muito restritos: a cooperação social com base no respeito mútuo era considerada impossível entre aqueles que professavam uma fé diferente ou uma concepção do bem diferente. O liberalismo nasce neste contexto com o desenvolvimento de diversos argumentos a favor da tolerância religiosa. No século XIX, com Constant, Tocqueville e Mill, a moralidade política liberal foi aprimorada tendo em vista o contexto do Estado democrático moderno em nascimento. Um dos pressupostos centrais do liberalismo é "que cidadãos iguais têm concepções do bem diferentes e até

${ }^{18}$ Liberalismo Político... op. cit., p. 357. 
mesmo irreconciliáveis e incomensuráveis. Numa sociedade democrática moderna, a existência dessas formas de vida distintas é vista como uma condição normal, que só poderia ser eliminada pelo uso autocrático do poder estatal". ${ }^{19}$

A moralidade política liberal aceita esse pluralismo de concepções do bem como um fato da vida moderna; considera-o como algo desejável desde que a pluralidade possa ser acomodada num sistema de liberdades fundamentais iguais, de modo que sejam realizados os muitos benefícios da diversidade humana. Uma teoria da justiça deve fornecer princípios justificados de modo razoável e público para que "a união social não se fundamente mais numa concepção do bem, tal como dada por uma fé religiosa ou uma doutrina filosófica, mas numa concepção pública e compartilhada de justiça apropriada à concepção de cidadãos de um Estado democrático como pessoas livres e iguais". ${ }^{20} \mathrm{O}$ ideal político a ser realizado no mundo social é o da autonomia plena dos cidadãos: "a autonomia plena inclui não apenas a capacidade de ser racional, mas também a capacidade de promover nossa concepção do bem de formas compatíveis com o respeito aos termos equitativos de cooperação social, isto é, os princípios de justiça". ${ }^{21}$

Como sabemos, Rawls elabora um procedimento complexo de justificação que abarca diferentes níveis de generalidade para justificar a escolha dos princípios de justiça: o procedimento de deliberação e escolha dos princípios na posição original e o método do equilíbrio reflexivo cujo ápice é o consenso sobreposto. ${ }^{22}$ Mas mais do que um procedimento, Rawls introduz elementos substantivos na justificação dos princípios: os bens primários (ou bens básicos). "A ideia central é que os bens primários são selecionados perguntando-se pelas coisas que são geralmente necessárias como condições sociais e meios polivalentes para possibilitar às pessoas realizar suas concepções específicas do bem e desenvolver suas duas capacidades morais". ${ }^{23}$ Os bens primários são: a) as liberdades fundamentais, como condições institucionais essenciais e necessárias para o desenvolvimento e exercício pleno e bem informado das duas capacidades morais dos cidadãos;

\footnotetext{
19 Idem, p. 358.

20 Idem, p. 359.

21 Idem, p. 360.

${ }^{22}$ Por uma questão de economia do texto, não examinarei aqui os detalhes do procedimento de justificação. Cf. WERLE, D. L. Justiça e ..., op. cit.

${ }^{23}$ Idem, Liberalismo político, p. 362.
} 
são indispensáveis para a proteção de um amplo leque de concepções específicas do bem; b) a liberdade de movimento e de escolha de ocupação num contexto de oportunidades variadas, que permitem a realização de diversos fins últimos e a possibilidade de levar a cabo uma decisão de revisálos e mudá-los, se o desejarmos; c) os poderes e prerrogativas de posições e cargos de responsabilidade, que abrem espaço para várias capacidades sociais e de autonomia do self; d) renda e riqueza, entendidos como meios polivalentes necessários para realizar direta ou indiretamente uma grande variedade de fins, quaisquer que sejam; e) as bases sociais do auto-respeito, que incluem aqueles aspectos das instituições básicas em geral essenciais para que os cidadãos tenham um vigoroso sentimento de seu próprio valor como pessoas, e para que sejam capazes de desenvolver e exercer suas capacidades morais e de promover seus objetivos e fins com auto-confiança. ${ }^{24}$

$\mathrm{O}$ argumento de Rawls é que "as liberdades fundamentais são, na verdade, bens primários”, 25 e sua importância é justificada enquanto condições formais e materiais necessárias ao desenvolvimento da autonomia plena das pessoas como indivíduos e cidadãos. Em outros termos, as liberdades fundamentais e sua prioridade e o valor equitativo das liberdades políticas são justificadas tendo em vista sua importância no desenvolvimento das duas capacidades morais que caracterizam os cidadãos livres e iguais de uma sociedade democrática e assim são fundamentais para estabilizar uma cooperação social justa. Vale destacar aqui que Rawls não está pensando apenas na questão redistributiva, mas principalmente nas bases sociais do auto-respeito. $\mathrm{O}$ auto-respeito baseia-se em nossa autoconfiança enquanto membros plenamente cooperativos da sociedade; ele proporciona um sentimento seguro do próprio valor, uma convicção firme de que vale a pena procurar realizar sua própria concepção do bem. Ele depende de e é incentivado por certas características públicas das instituições sociais básicas, de como elas funcionam juntas e como se espera que as pessoas aceitem esses arranjos considerem e tratem umas às outras. $\mathrm{O}$ sentimento de nosso próprio valor, assim como nossa autoconfiança, depende do respeito e da reciprocidade que os outros demonstram ter por nós. E são as liberdades fundamentais que asseguram as condições sociais e políticas que tornam possível que os cidadãos expressem seu respeito mútuo uns pelos outros

\footnotetext{
24 Idem, p. 363.
}

25 Idem, p. 364 
enquanto indivíduos razoáveis e dignos de confiança, assim como seu reconhecimento do valor que todos os cidadãos atribuem à própria forma de vida. Elas servem ao propósito público comum de assegurar a justiça a cada cidadão, enquanto pessoa moral livre e igual, em uma base de respeito mútuo, fazendo com que os vínculos de reciprocidade se estendam à sociedade como um todo. ${ }^{26}$

Mas, é claro, as liberdades fundamentais não podem ser vistas como mera formalidade. A concepção da justiça como equidade preocupa-se, principalmente com a formulação do segundo princípio da justiça, com os meios materiais necessários para os cidadãos usarem efetivamente suas liberdades iguais e de realizarem seus planos de vida. Muitos argumentaram, principalmente os democratas radicais e os socialistas, que, embora possa parecer que os cidadãos são efetivamente iguais, são demasiado grandes as desigualdades sociais e econômicas e que aqueles com maior riqueza e responsabilidade podem controlar a elaboração legislativa em benefício próprio.

É justamente por ter em vista esse tipo de assimetria no uso efetivo das liberdades que Rawls faz a distinção entre as liberdades fundamentais iguais formalmente asseguradas e o valor real dessas liberdades. As liberdades fundamentais especificam os direitos e deveres institucionais entre os cidadãos. Obviamente a falta de informação, a pobreza e a ausência de meios materiais em geral impedem as pessoas de exercerem seus direitos e de tirar proveito dessas possibilidades. São fatores que atingem o valor das liberdades, isto é, o proveito que as pessoas tiram de suas liberdades. Enquanto que as liberdades fundamentais são as mesmas para todos os cidadãos, o valor da liberdade não é o mesmo para todos. Para tornar mais efetivo o uso das liberdades, Rawls confere atenção especial à dimensão da autodeterminação política. Apenas as liberdades políticas merecem um tratamento especial por parte de Rawls, "incluindo no primeiro princípio de justiça a garantia de que às liberdades políticas, e apenas a essas liberdades, se assegura (...) seu valor equitativo", 27 no sentido de que todos os cidadãos tenham uma oportunidade equitativa de assumir um cargo público e influenciar o resultado de decisões políticas. Rawls denomina o princípio da liberdade igual, quando aplicado ao procedimento político, princípio de igual

\footnotetext{
26 idem, p. 374 ,
}

27 idem, p. 383. 
participação: "exige que todos os cidadãos tenham um direito igual de participar do processo constituinte que define as leis às quais devem obedecer, bem como seus resultado igual" 28 .

A garantia do valor equitativo das liberdades políticas tem como principal finalidade assegurar "a cada cidadão um acesso equitativo e aproximadamente igual ao uso de um recurso público destinado a promover um certo propósito político, a saber, o recurso público especificado pelas normas e procedimentos constitucionais que governam o processo político e controlam o acesso a posições de autoridade política". ${ }^{29}$ Uma vez que consideramos o papel peculiar do processo político na determinação das leis e políticas que devem regular a estrutura básica, torna-se mais evidente para Rawls que as liberdades políticas devem ser objeto da garantia especial do valor equitativo. "Para que o fórum público seja livre e aberto a todos, e permaneça em sessão contínua, todos devem poder participar dele. Todos os cidadãos devem ter os meios de informar-se sobre questões políticas. Devem ter condições de avaliar como certas propostas interferem em seu bem-estar e quais políticas promovem sua concepção do bem público. Além disso, devem ter uma oportunidade eqüitativa de acrescentar à agenda propostas alternativas para o debate público." 30 Claro, Rawls não está afirmando que a vida política e a participação de todos no autogoverno sejam consideradas bens proeminentes para cidadãos plenamente autônomos. A valorização da participação política em si é uma concepção do bem entre outras. O que importa a Rawls é a ideia de um sistema de liberdades básicas iguais que se expressa na constituição - "o mais elevado sistema de normas sociais para a criação de normas" 31 , definidas num processo constituinte. "A garantia do valor equitativo para as liberdades políticas é incluída no primeiro princípio de justiça porque resulta essencial para estabelecer uma legislação justa e também para assegurar que o processo político equitativo especificado pela constituição esteja aberto a todos numa base de igualdade aproximada." 32

\footnotetext{
28 idem, Uma teoria... op. cit., p. 273.

${ }^{29}$ Liberalismo político...op. cit., p. 384.

30 Idem, Uma teoria..., op. cit., p. 277-278.

31 Idem ,Uma teoria....op. cit., p. 273.

32 Liberalismo político...op.cit., p.386-7. Além disso, a liberdade política também se justifica por outros efeitos: "a vontade pública de consultar e levar em conta as convicções e interesses de todos estabelece as bases da amizade cívica e modelo o ethos da cultura política (...) O resultado do autogoverno, quando os direitos políticos iguais tem seu valor equitativo garantido, é aumentar a auto-estima e 0 senso de capacidade política do cidadão comum". Idem, Uma teoria da justiça...., op. cit., p. 289.
} 
As liberdades fundamentais especificam o status comum e garantido dos cidadãos iguais numa sociedade democrática bem ordenada. "A liberdade é um padrão de convivência determinado por formas sociais". ${ }^{33}$ Ela é produzida pelas instituições sociais, políticas e jurídicas da sociedade. A ênfase está na organização de uma sociedade justa e livre. Segundo uma sugestão de Albrecht Wellmer, ${ }^{34}$ a compreensão que Rawls tem da realização das liberdades é muito próxima ao modo de Hegel entender a realização da ideia de liberdade na Filosofia do Direito. Uma vez que o objeto primeiro da justiça é a estrutura básica da sociedade - que abrange, como vimos antes, as instituições da família, da propriedade, do mercado e do rule of law podemos ver no liberalismo político de Rawls uma concepção de justiça que abrange os vários momentos ou dimensões de realização de uma concepção universal de liberdade comum, que acabaria se concretizando numa eticidade democrática. Ela abrange diferentes esferas de auto-realizações dos seres humanos. Mas diferente de Hegel, em Rawls a passagem do direito abstrato à eticidade concreta se daria de forma mais democrática, já que o princípio da liberdade igual conduz diretamente a um princípio de direitos iguais de participação política e de deliberação pública.

Assim, diferente da interpretação de Habermas, o que o liberalismo político de Rawls propõem é, portanto, uma forma de combinar pelo menos dois tipos familiares de direitos e liberdades básicos, as chamadas liberdades dos antigos e as liberdades dos modernos. Os dois tipos de liberdades aparecem por igual no primeiro princípio de justiça adotado na posição original. Para Rawls derivam de uma mesma raiz: o conceito de autonomia. Rawls entende a autonomia como autonomia política plena, e não meramente como autonomia moral. A autonomia moral seria uma ideia muito mais ampla que pertence a determinadas doutrinas abrangentes, como o liberalismo de Kant e Mill. Na definição de Rawls "a autonomia política se concretiza em termos de várias instituições e práticas políticas, bem como se expressa também em certas virtudes políticas de cidadãos em seu pensamento e sua conduta - suas discussões, suas deliberações e suas decisões - ao levar

\footnotetext{
${ }_{33}$ Uma Teoria da Justiça..., op. cit., p. 77.

34 WELLMER, A.. "Condiciones de una cultura democrática: sobre el debate entre 'liberales' y 'comunitaristas'". In: WELLMER, A.. Finales de Partida: La Modernidad Irreconciliable. Tradução: Manuel Jímenez Redondo. Madrid: Cátedra, 1996, p.77-101.
} 
adiante um regime constitucional". ${ }^{35}$ Os cidadãos alcançam a plena autonomia política quando vivem sob uma constituição razoavelmente justa que garanta sua liberdade e igualdade, com todas as leis e preceitos subordinados adequados que regulam a estrutura básica, e quando compreendem plenamente e confirmam esta constituição e suas leis, bem como as ajustam e revisam à medida que as mudanças sociais o exigerem, sempre convenientemente movidos por um senso de justiça e pelas demais virtudes políticas. Nenhuma teoria pode antecipar todas as razões e argumentos envolvidos na resolução dos conflitos sobre as questões política fundamentais. "O ideal de uma constituição justa é sempre algo que terá de ser elaborado progressivamente" ${ }^{36}$ pelos próprios cidadãos envolvidos na deliberação pública, a partir de suas reflexões e experiências com as instituições e a vida prática de uma sociedade democrática.

Levando em consideração esse conceito de autonomia, não faz sentido dizer que o liberalismo político defende uma esfera de liberdade prepolítica ou que as liberdades básicas se situam num domínio prepolítico. No liberalismo político as liberdades básicas podem ser interpretadas dessa maneira. Certamente, Rawls segue o pensamento liberal ao colocar um conjunto de liberdades básicas fundamentais como um limite inviolável que a soberania popular (a regra da maioria) não pode ultrapassar. ${ }^{37}$ Geralmente, essas liberdades básicas se encontram incorporadas na constituição e são protegidas por direitos constitucionais com base nas deliberações e juízos dos cidadãos ao longo do tempo. Porém, "aceitar uma constituição que restringe a regra da maioria não precisa, pois, ser anterior à vontade do povo e, por conseguinte, não expressa necessariamente uma constrição externa sobre a soberania popular. É a vontade do povo expressa em procedimentos democráticos como a ratificação de uma constituição e as promulgações de emendas”. ${ }^{38}$ A proteção das liberdades básicas não é prévia à formação política da opinião e da vontade: na verdade, são sujeitas ao poder constituinte do povo para formar, ratificar e emendar uma constituição. A incorporação das liberdades fundamentais numa constituição é algo que deve

\footnotetext{
35 RAWLS, J. "Réplica a Habermas", in: HABERMAS, J.; RAWLS, J. (1998). Debate sobre el liberalismo político. Tradução de Gerard Vilar Roca. Barcelona: Paidós, 1998, p. 106.

${ }^{36}$ Idem, p. 106.

${ }^{37}$ Trata-se de uma das dimensões da tese da primazia da justiça sobre o bem: a inviolabilidade da pessoa.

38 Idem, p. 111.
} 
ser decidido pelo poder constituinte do povo democrático. ${ }^{39}$ Rawls tem uma compreensão dinâmica constituição como um projeto inacabado. Dessa perspectiva de longo prazo, o Estado constitucional democrático não representa uma estrutura acabada, mas uma realização delicada e acima de tudo falível e revisável, cujo propósito é realizar novamente o sistema de direitos em circunstâncias cambiantes, ou seja, interpretar melhor o sistema de direitos, institucionalizá-lo mais apropriadamente, e formular seus conteúdos mais radicalmente. Essa é a perspectiva deriva do próprio caráter indeterminado dos princípios da justiça: são eles que produzem na realização do sistema de direitos, numa linguagem habermasiana, a tensão entre facticidade e validade social e motivam os cidadãos na busca da superação do hiato entre o ideal da sociedade justa e a realidade concreta das instituições. A seqüência de quatros estágios de aplicação dos princípios de justiça prevista na teoria ideal - expressa "a ideia de que as liberdades dos modernos estão sujeitas à vontade constitucional do povo". ${ }^{40}$

Assim, a institucionalização das liberdades básicas numa dada constituição não é um assunto da teoria, mas depende da prática constituinte de um povo democrático que vai decidir qual o melhor desenho institucional para realizar o ideal de uma sociedade justa entre cidadãos livres e iguais. Essa prática constituinte "pressupõem os princípios do direito e da justiça, mas também requere o estudo da história e um conhecimento a fundo do funcionamento das instituições democráticas sob modelos particulares de condições históricas, culturais e sociais. $\mathrm{Na}$ justiça como equidade, este é um juízo que deve realizar-se numa assembléia constitucional, com a exposição dos prós e contras valorados a partir deste ponto de vista [...] A questão é que o desenho institucional não é um assunto que deva resolver-se somente por meio de uma concepção filosófica da justiça nem unicamente por um estudo político e social, mas sim por um exame caso a caso de exemplos e tendo em conta a história política particular e a cultura democrática da sociedade em questão". ${ }^{41}$ Assim, Rawls sustenta que no liberalismo político não há uma competição não resolvida entre as liberdades dos antigos e a dos modernos:

\footnotetext{
39 Idem, p. 122.

40 Idem, p. 112.

${ }^{41}$ Idem, p. 122-3. Na seqüência de sua réplica a Habermas, Rawls aponta uma série de seis passos para tornar vincular as liberdades num sistema plenamente adequado. Não analisarei esses passos aqui, novamente por uma questão de espaço.

${ }^{41}$ RAWLS, J. "A ideia de razão pública revisitada". In: WERLE, D.; MELO, R. S.(org.). Democracia deliberativa. São Paulo: Esfera Pública, 2007, p.150
} 
trata-se de uma questão de ponderar e deliberar sobre qual o sistema de liberdades iguais é mais adequado considerando a dinâmica cultural, social, política, as relações de poder de determinada sociedade. ${ }^{42}$

Bom, se não há uma concorrência não resolvida entre autonomia privada e autonomia pública no liberalismo político de Rawls, ainda persiste o problema de como pensar como se dá o vínculo legítimo do poder com a lei de modo a realizar a justiça, se nenhuma lei moral pode ser imposta externamente sobre um povo soberano democrático. Aqui as ideias de razão pública e o princípio liberal de legitimidade política desempenham um papel importante.

Rawls define a razão pública como sendo a característica de um povo democrático: é a razão dos cidadãos, daqueles que compartilham o status de cidadania igual. "A ideia de razão pública surge de uma concepção de cidadania democrática numa democracia constitucional”. ${ }^{43}$ Ela é expressão de uma relação política fundamental: a da cidadania democrática, tanto do ponto de vista da relação entre cidadãos no interior da estrutura básica, quanto do ponto de vista do exercício do poder político. Nesse último ponto de vista, "razão pública é a razão dos cidadãos iguais que, enquanto corpo coletivo, exercem um poder político final e coercitivo uns sobre os outros ao promulgar leis e emendar sua constituição". 44 A razão pública pode ser entendida como um "universo do discurso" constituído pelo uso do conhecimento teórico e prático por parte dos cidadãos ao formarem seus juízos políticos e tomarem as decisões comuns. Nesse sentido, delimita o campo onde deve mover-se a deliberação pública sobre as questões políticas fundamentais.

A forma e o conteúdo da razão pública são "parte da própria ideia de democracia”: funcionam como um princípio de legitimação do poder, que define, no nível mais profundo, as normas morais e os valores políticos básicos que devem determinar a relação de um governo democrático com seus cidadãos e a forma de reconhecimento político que os cidadãos devem estabelecer entre si como livres e iguais. "Enquanto razoáveis e racionais, e

\footnotetext{
${ }^{42} \mathrm{Na}$ seqüência de sua réplica a Habermas, Rawls aponta uma série de seis passos para tornar vincular as liberdades num sistema plenamente adequado. Não analisarei esses passos aqui, novamente por uma questão de espaço.

${ }^{43}$ RAWLS, J. "A ideia de razão pública revisitada". In: WERLE, D.; MELO, R. S.(org.). Democracia deliberativa. São Paulo: Esfera Pública, 2007, p.150.

${ }^{44}$ Liberalismo político..., op. cit., p.263
} 
sabendo-se que endossam uma grande diversidade de doutrinas religiosas e filosóficas razoáveis, os cidadãos devem estar dispostos a explicar a base de suas ações uns para os outros em termos que cada qual razoavelmente espere que outros possam aceitar, por serem coerentes com a liberdade e igualdade dos cidadãos. Procurar satisfazer essas condições é uma das tarefas que esse ideal de política democrática exige de nós. Entender como se comportar enquanto cidadãos democráticos inclui entender um ideal de razão pública". ${ }^{45}$ Em suma, diz respeito a como a relação política deve ser entendida. A ideia de razão pública está implícita na própria relação política fundamental da cidadania democrática em uma democracia constitucional. A razão pública expressa duas relações: a relação dos cidadãos com a estrutura básica da sociedade, no sentido de que oferece um conjunto de princípios e valores políticos que os cidadãos devem seguir para orientar a formação de seus juízos sobre questões políticas fundamentais; e segundo, a relação de reconhecimento recíproco dos cidadãos livres e iguais entre si, que exercem poder político último como um corpo coletivo.

Essas duas relações aparecem no princípio liberal de legitimidade política, segundo o qual o poder político deve ser exercido, pelo menos quando fundamentos constitucionais e questões de justiça básica estiverem em jogo, de modo tal que todos os cidadãos possam endossá-lo publicamente à luz de sua própria razão. É esse o princípio de legitimidade a ser preenchido pela justiça como equidade. Dado o fato do pluralismo razoável e os problemas de justificação pública colocados pelos conflitos que dele decorrem, a questão que está subjacente ao princípio liberal de legitimidade é a seguinte: "de acordo com quais ideais e princípios, então, os cidadãos que compartilham igualmente o poder político definitivo têm de exercer tal poder de forma que cada um possa justificar razoavelmente suas decisões políticas a todos?" 46

Um dos principais critérios que este princípio de legitimidade deve satisfazer, e que, consequentemente, está no cerne da ideia rawlsiana de democracia deliberativa, é o critério de reciprocidade. Este exige a justificação pública dos termos da cooperação social, de modo que seja razoável que as pessoas, enquanto cidadãos livres e iguais, possam aceitá-los à luz da sua própria razão, e "não enquanto dominados ou manipulados, ou sob a

\footnotetext{
45 Idem, p. 267.
}

46 Idem, p. 150. 
pressão de uma posição política ou social inferior”. Consequentemente, o padrão de legitimidade política expresso pela ideia de justificação pública fundamentada no critério de reciprocidade diz o seguinte: "nosso exercício do poder político é apropriado somente quando acreditamos sinceramente que as razões que poderíamos oferecer para nossas ações políticas (...) são suficientes, e pensamos, além disso, que outros cidadãos também poderiam aceitar razoavelmente aquelas razões". ${ }^{47}$

A ideia de Rawls é que o princípio da reciprocidade expresso na razão pública traduz a relação política em um regime democrático constitucional como sendo semelhante àquela da "amizade cívica" ${ }^{48} \mathrm{~A}$ ideia básica é que as questões políticas fundamentais devem ser decididas não por razões que expressam alguma verdade última (religiosa ou secular), mas por razões que poderiam ser compartilhadas por todos os cidadãos enquanto livres e iguais. A moralidade política liberal considera a crença numa verdade última como sendo incompatível com a cidadania democrática e a ideia de direito legítimo. A razão pública tem, portanto, um caráter mais destacadamente normativo do que epistêmico.

Essa é a base, para Rawls, do conceito de democracia deliberativa. O cerne normativo dessa concepção de democracia reside na própria ideia de deliberação. Quando os cidadãos deliberam, eles trocam pontos de vista, debatem e defendem as razões apresentadas para fundamentar determinados juízos e decisões sobre questões políticas fundamentais. Eles supõem que suas opiniões e juízos políticos podem ser revisados pela discussão com outros cidadãos; e, portanto, opiniões e juízos não são simplesmente o resultado fixo de interesses privados ou não políticos existentes antes da deliberação. É neste ponto que a razão pública é crucial, pois ela caracteriza essa argumentação dos cidadãos no que diz respeito aos elementos essenciais da constituição e às questões de justiça básica.

As normas morais e os valores políticos da razão pública devem assegurar as condições normativas para uma cidadania democrática orientada para a realização do ideal de cooperação social fundado no respeito mútuo. Rawls reforça a ideia de que a razão pública é uma concepção ideal de cidadania para um regime democrático, e ela descreve o que deve ser, e não necessariamente como funcionam realmente as deliberações e decisões

\footnotetext{
47 Idem, p. 150-51.
}

48 Idem, p. 151. 
políticas nas democracias. Contudo, não se trata de um dever ser contraposto abstratamente à realidade política das instituições. Para Rawls, a razão pública expressa também o que é possível e pode vir a ser, uma vez que seu conteúdo e procedimento já estariam, pelo menos parcialmente, implícitos na cultura política pública das democracias constitucionais modernas, no fórum político público, composto: a) pelo discurso dos juízes em suas decisões, especialmente juízes da Suprema Corte; b) no discurso dos que ocupam cargos públicos, especialmente o chefe do Executivo e os membros das assembleias legislativas; c) no discurso dos candidatos a cargos públicos e administradores de campanhas, especialmente sua oratória pública, plataformas de partidos e posições políticas. O importante é que a deliberação pública tem de se tornar possível, ser "reconhecida como uma característica básica da democracia e libertar-se do curso do mercado. De outra forma, a política permanecerá dominada por interesses corporativos, e outros interesses organizados, que por meio de largas contribuições para campanhas distorcem ou mesmo excluem a discussão pública e a deliberação". 49

Com essas características, a democracia deliberativa delimita as razões que podem ser apresentadas nos fóruns de discussão de questões políticas fundamentais àquelas razões que não violem a reciprocidade entre cidadãos livres e iguais. Isso não fixa, de uma vez por todas, as características da razão pública em favor de uma determinada concepção de justiça. A razão pública fica aberta a um conjunto de concepções diferentes de justiça e democracia. A única exigência é que a razão pública seja exercida segundo concepções políticas da justiça que tenham as seguintes características: seus princípios se aplicam à estrutura básica da sociedade; podem ser apresentadas independentemente de doutrinas abrangentes; e somente podem ser testadas a partir das ideias fundamentais implícitas na cultura política pública de uma democracia constitucional. Essa exigência permite que os cidadãos possam introduzir, a qualquer momento, na discussão política pontos de vista de suas doutrinas abrangentes (religiosas ou não-religiosas), contanto que possam oferecer devidamente razões públicas para apoiar os princípios e políticas que as doutrinas dizem apoiar. ${ }^{50}$

\footnotetext{
${ }^{49}$ A ideia de razão pública..., op. cit., p. 153. Como implicações imediatas da ideia de democracia deliberativa, Rawls cita o financiamento público de campanhas e a realização de reuniões e encontros públicos de debate e deliberação sobre questões políticas fundamentais.

50 Idem, p. 157.
} 
A razão pública, então, acaba funcionando como um padrão para estabelecer os limites da tolerância e para avaliar as reivindicações conflitantes dos cidadãos, principalmente aquelas que se referem às questões políticas fundamentais (fundamentos constitucionais e justiça básica). Um dos papéis da razão pública é abrandar os conflitos que derivam da diversidade de valores e doutrinas e encorajar a estabilidade social. No desempenho dessa função, é fundamental que a razão pública não critique nem ataque qualquer doutrina abrangente, exceto à medida que tal doutrina seja incompatível com os valores e princípios fundamentais da razão pública e, portanto, com as ideias intuitivas de uma comunidade política democrática. A exigência básica é que uma doutrina razoável aceite um regime democrático constitucional e a ideia complementar de lei legítima.

Nesse sentido, a razão pública é a instância privilegiada por Rawls para pensar como a justiça como equidade pode conseguir obter tanto a aceitabilidade racional para suas pretensões normativas, como também ser objeto da aceitação fática por parte dos cidadãos. A justiça como equidade busca expressamente conquistar o apoio refletido de cidadãos que endossam doutrinas abrangentes e razoáveis, embora conflitantes. Como dito acima, busca conquistar seu apoio dirigindo-se à razão de cada cidadão. Somente assim ela pode ser também uma concepção da legitimidade da autoridade política. Uma concepção de legitimidade política que tem por objetivo uma base pública de justificação apela para a razão pública e, consequentemente, para cidadãos livres e iguais considerados razoáveis e racionais.

O cerne da ideia de razão pública manifesta-se na noção de razoabilidade, que aparece nela como "dever moral (não legal)", "dever de civilidade”, uma virtude segundo a qual os cidadãos cultivam a disposição de se justificarem uns aos outros de modo que os princípios, direitos e políticas que defendem ou reivindicam possam ser razoavelmente sustentados na razão pública. Rawls acrescenta que o dever de civilidade também envolve a disposição de ouvir os outros e uma equanimidade (fairmindedness) ao decidir quando seria razoável fazer ajustes em suas próprias concepções.

Mas não basta o dever de civilidade. Este tem de ser exercido junto com os valores políticos expressos na justiça como equidade. Estes são de dois tipos: a) os próprios valores da justiça política - expressos nos princípios da igualdade e liberdade política e civil, da igualdade de oportunidades e da igualdade social e reciprocidade - e os valores expressos na lista de bens primários; b) os valores da razão pública formados pelas diretrizes de 
indagação: as regras de evidência, os princípios de argumentação e de inferência válidos, a razoabilidade, o dever de civilidade. Assim, diz Rawls, "a união do dever de civilidade com os grandes valores do político produz o ideal de cidadãos governando a si mesmos, de um modo que cada qual acredita que seria razoável esperar que os outros aceitem; e esse ideal, por sua vez, é sustentado pelas doutrinas abrangentes que pessoas razoáveis defendem. Os cidadãos defendem o ideal da razão pública não em conseqüência de uma barganha política, como num modus vivendi, mas em virtude de suas próprias doutrinas razoáveis". ${ }^{51}$

A questão que surge aqui é por que os cidadãos deveriam respeitar os limites da razão pública. O que tem de ser demonstrado é se o respeito à razão pública se deve em decorrência da exigência de direitos e liberdades individuais fundamentais, ou se decorre do fato de promover certos valores importantes presentes na autocompreensão político-cultural da sociedade, ou de ambas as coisas. Para Rawls o "liberalismo político apóia-se na conjectura de que os direitos e os deveres assim como os valores em questão têm peso suficiente para que os limites da razão pública sejam justificados pelas avaliações globais das doutrinas abrangentes". ${ }^{52}$

A concepção de democracia deliberativa, entendida como cooperação política com base no respeito mútuo e no critério de reciprocidade, tem também um papel fundamental na realização dos princípios de justiça. Tratase de uma concepção de democracia com certas características do republicanismo clássico, particularmente a importância atribuída às virtudes políticas e ao valor da participação política dos cidadãos na organização da coisa pública. Ao contrário da visão tradicional atribuída à moralidade política liberal, segundo a qual o que importa é a liberdade negativa e a autonomia privada dos cidadãos, Rawls argumenta a favor da centralidade da participação e das liberdades políticas: "as virtudes da cooperação política são muito importantes. Refiro-me, por exemplo, às virtudes da tolerância e da disposição de fazer concessões mútuas, assim como à virtude da razoabilidade e do senso de justiça. Quando essas virtudes estão disseminadas na sociedade e sustentam sua concepção política da justiça, constituem um grande bem público, parte do capital político da sociedade". ${ }^{53}$ E essas

\footnotetext{
51 Liberalismo Político..., op. cit., p.266.

52 idem, p. 268.

53 Idem, p. 203-4.
} 
virtudes estão ligadas à vontade de cooperar com os outros em termos políticos que todos possam aceitar publicamente.

Talvez seja mais plausível, do ponto de vista prático, esperar que os cidadãos que professam diferentes doutrinas abrangentes compartilhem esse princípio liberal de legitimidade e de razão pública do que princípios substantivos de justiça.

\section{REFERÊNCIAS BIBLIOGRÁFICAS}

HABERMAS, J. "Reconciliación mediante el uso público de la razón” In: HABERMAS, J.; RAWLS, J.(1998). Debate sobre el liberalismo político. Tradução de Gerard Vilar Roca. Barcelona: Paidós, 1998

HART, H. L. A. "Rawls on liberty and its priority" in: DANIELS, N. (ed.) Reading Rawls. Oxford: Basil Blackwell, 1975.

RAWLS, J. Uma teoria da justiça. Trad. de Almiro Pisetta e Lenita M.R.Esteves. São Paulo: Martins Fontes, 2002.

. "Justiça como equidade: uma concepção política, não metafísica”. In: Lua Nova, n. 25, 1992.

. O liberalismo político. Trad. Dinah de Abreu Azevedo. São Paulo: Ática, 2000

- Justiça como equidade: uma reformulação. Tradução de Cláudia Berliner. Revisão técnica e da trad. Álvaro de Vita. São Paulo: Martins Fontes, 2003.

. "Réplica a Habermas", in: Habermas, Jürgen; Rawls, John (1998). Debate sobre el liberalismo político. Tradução de Gerard Vilar Roca. Barcelona: Paidós, 1998.

. "A ideia de razão pública revisitada”. In: WERLE, D. L.; MELO, R. S. (org.). Democracia deliberativa. São Paulo: Esfera Pública, 2007. 
WELLMER, A. "Condiciones de una cultura democrática: sobre el debate entre 'liberales' y 'comunitaristas'”. In: WELLMER, A. Finales de Partida: La Modernidad Irreconciliable. Tradução: Manuel Jímenez Redondo. Madrid: Cátedra, 1996, p.77-101.

WERLE, D. L. Justiça e democracia. Ensaios sobre John Rawls e Jürgen Habermas. São Paulo: Singular/Esfera Publica, 2008. 